\title{
Luigi Boccherini en la Ilustración española ${ }^{1}$
}

\author{
Jaume Tortella
}

El desarrollo del amplio «estado de la cuestión» con el que se abre esta tesis permite concluir que los estudios biográficos acerca de Luigi Boccherini requerían un esfuerzo de investigación para actualizar el conocimiento que de su vida se tenía, y para reparar los desórdenes y carencias que todavía oscurecían las más recientes investigaciones. Ese esfuerzo debía desarrollarse en tres órdenes básicos:

a) Deshacer y corregir los innumerables errores, lagunas y leyendas que habían venido poblando las descripciones vitales del músico, especialmente en la larga etapa española que se extiende desde 1768, cuando Boccherini llega a Madrid, a la edad de 25 años, hasta su muerte, en 1805; es decir, a lo largo de cerca de 40 años.

b) Abordar, de una vez por todas, el mito de la pobreza en la que los biógrafos habían querido sumir a Boccherini, en diversas etapas de su vida hispana, con especial énfasis en los últimos años y, particularmente, en el momento de su muerte.

c) Cubrir un vacío informativo de dos quinquenios, entre 1786 y 1797, a lo largo de los cuales se había renunciado a saber absolutamente nada acerca de las actividades, relaciones, problemas y devenir vital del compositor, siendo así que esa década, calificada en esta investigación como la década opaca, representa un segmento demasiado extenso como para quedar vacío de información, ya que alcanza a más del 25 por ciento del tiempo que el maestro vivió en España, y a un 16 por ciento del total de los 62 años que duró su vida.

Si éstas eran las tres áreas que requerían una paciente y sistemática labor de rastreo documental, no se puede decir que fueran las únicas, puesto que, a lo largo de las no muy numerosas biografías escritas sobre Boccherini, el lector se encuentra con un sin fin de contradicciones, errores y carencias, de distinto calado e importancia, pero que proyectan una alargada sombra de dudas acerca de la credibilidad

1. Tesis doctoral dirigida por el Dr. Ricardo García Cárcel, presentada en el Departament d'Història Moderna i Contemporània de la Universitat Autònoma de Barcelona, 1999. 
que esas semblanzas merecen. Cuestiones como el móvil real que decidió al maestro a trasladarse a Madrid y quedarse a vivir de forma permanente; como las dificultades o facilidades que encontró para situarse en la Corte; como las rencillas o amistades con otros músicos, tanto españoles como italianos, o de otra procedencia; como las circunstancias de sus dos matrimonios, y el número de hijos que tuvo; o como las fechas y las condiciones en que se empleó al servicio del infante don Luis de Borbón Farnesio, hermano del rey Carlos III..., son algunos de los aspectos biográficos más oscuros, en cuanto a los primeros años de la vida hispana del maestro, y en los que, habiendo caído los distintos biógrafos en errores u omisiones, la presente tesis ha podido poner en claro.

Parte de esos mismos errores y omisiones se proyectan también sobre las circunstancias y características de la música que el maestro escribe en esta etapa inicial, por lo que, a la nueva luz, puede situarse la producción musical en un contexto mucho más diáfano de la peripecia vital del maestro, así como en el ámbito más amplio de las condiciones sociales, económicas y políticas por las que atravesaba la monarquía hispana.

Durante la fase intermedia de la vida hispana de Boccherini, también abundan las incongruencias biográficas, pero lo más llamativo es la carencia absoluta de conocimientos acerca de lo que fue la vida del luqués en la década opaca. Por tanto, el hallazgo de una notable cantidad de documentos, directa o indirectamente relacionados con Boccherini, hasta ahora inéditos, ha permitido construir un sólido puente para unir las dos orillas de esa inquietante década opaca, entre 1786, momento en que el maestro se desvanecía ante la mirada de los biógrafos, y 1797, año en el que un breve epistolario de cartas enviadas por Boccherini a sus editores residentes en París, particularmente, a Ignaz Pleyel, habían permitido a los estudiosos recuperar el hilo vital del maestro.

En la presente investigación, se da a la luz una amplia colección de documentos, muchos de ellos con la firma del propio Boccherini, mediante los cuales podemos ver cómo este hombre, metódico, consciente y serio, organizó su vida, tras vivir la amarga experiencia de ver morir a su primera esposa, Clementina Pellicia, en abril de 1785 y, en agosto, a su gran mecenas, don Luis de Borbón. Dicha serie documental, muy variada y, en gran parte, dispersa por diferentes archivos y ciudades castellanas, nos muestra a Boccherini cuidando de la seguridad de sus hijos huérfanos y casándose en segundas nupcias con María del Pilar Joaquina Porreti, hija de un colega intérprete, como él, del violoncelo, de nombre Domingo Porreti. Vemos, también, cómo administra y hace inventario de su patrimonio y de los bienes parafernales de su nueva esposa; cómo le afectan los acontecimientos revolucionarios del país vecino; y cómo, tras una fuerte crisis de creación musical, se recupera con la subida al poder del conde de Aranda.

Así, las oscilaciones y la idiosincrasia de las composiciones musicales boccherinianas adquieren nueva luz, al desvanecerse gran parte de las sombras que oscurecían la vida del maestro, máxime cuando dichas composiciones se insertan constantemente en el devenir histórico de los reinos hispanos.

Por último, en la etapa final de la vida de Boccherini tampoco han faltado los equívocos biográficos y las omisiones, dando una visión del maestro harto defor- 
mada. Pero, de nuevo, el alumbramiento de series documentales inéditas ha permitido trazar, en detalle, el epílogo de la vida de un hombre que, lejos de haber quedado abandonado en la indigencia, mantuvo siempre un nivel de vida más que digno, con momentos, incluso, de opulencia. Y, para ofrecer el debido apoyo econométrico a esta afirmación, que destruye el mito de la pobreza, la tesis ofrece un capítulo dedicado a calibrar el nivel de vida de los Boccherini, a través de una cesta de la compra, basada en los ingresos, conocidos ahora con suficiente detalle, y en los gastos, elaborados mediante las adecuadas hipótesis, con el apoyo de las series de precios de Earl Hamilton, y Reher y Ballesteros. El cómputo de dichos gastos se pondera mediante el número de miembros de la familia, en los distintos años, y la correspondiente escala de coeficientes de gasto, según ese número de familiares. En cuanto a los ingresos, también se introducen, adecuadamente, los bienes patrimoniales, tanto de Boccherini como de su segunda esposa, $\mathrm{M}^{\mathrm{a}}$ del Pilar Porreti. De todo ello se deduce, sin lugar a duda alguna, que Boccherini nunca rozó la pobreza y que murió en una situación de holgura económica como para dejar un cierto patrimonio hereditario a los dos únicos hijos que le sobrevivieron, Josef Mariano, archivero, y Luis Marcos, presbítero.

En definitiva, esta tesis ofrece una nueva imagen del maestro italo-español y una nueva visión de su producción musical, inserta en una descripción del contexto social, económico y político de la segunda mitad del siglo XVIII hispano, que completa el escenario en el cual se desarrollaron la vida y el trabajo de este artista universal, a lo largo de sus últimos 37 años. 


\title{
Guerra, economia i política a la Catalunya de l'alta edat moderna ${ }^{1}$
}

\author{
Oriol Junqueras i Vies
}

Aquest treball intenta fer una aproximació a l'evolució de l'economia catalana durant l'alta edat moderna. Un tema que, bàsicament, només compta amb dos antecedents bibliogràfics. El primer, Jaume Carrera Pujal, en una obra publicada el 1946, aportant una quantitat molt important de referències documentals; però amb un significatiu dèficit interpretatiu i, fins i tot, d'ordenació temàtica i cronològica. El segon, Pierre Vilar, amb una obra extraordinària; però conclosa fa gairebé quatre dècades i que no tenia com a objectiu central l'anàlisi del període estudiat en aquest treball.

Des d'aleshores - $\mathrm{i}$ en línies generals-, l'esquema interpretatiu, les idees fonamentals i els marcs cronològics apuntats per Vilar han estat repetits incessantment. I, malgrat que s'han fet esforços valuosos per conèixer alguns aspectes concrets de l'economia dels segles XVI i XVII, no se n'ha revisat el marc general $^{2}$. I, en qualsevol cas, resulta evident que moltes qüestions importants resten encara sense resposta.

Quina incidència va tenir la política exterior de la monarquia sobre les activitats comercials? Quina va ser la incidència de la guerra i de la pau? Quin era el pes relatiu d'Itàlia i Castella en l'economia catalana? És cert que al llarg del segle XVI Catalunya mira cada vegada més cap a l'Atlàntic i menys cap al Mediterrani? Quines interrelacions podem establir entre creixement econòmic, augment demogràfic, fluxos migratoris i reordenacions territorials? Quina és la incidència de les fluctuacions econòmiques en la vida política interna de Catalunya i en les seves relacions amb la monarquia? Com van repercutir les experiències acumulades durant el segle XVI, en el pensament polític i econòmic de les primeres dècades del segle XVII? Fins a quin punt la praxi política i econòmica de les conflictives dues dècades que precedeixen el 1640 depèn d'aquest pensament que és fruit de les experiències acumulades durant més d'una centúria? Quina és la cronologia de tots aquests esdeveniments? Es tracta de processos uniformes o amb canvis de velocitat i, fins i tot, de sentit? ${ }^{3}$.

1. Treball d'investigació de 9 crèdits presentat el 1999 i dirigit per Antoni Simon i Tarrés, catedràtic del Departament d'Història Moderna i Contemporània de la Universitat Autònoma de Barcelona.

2. Possiblement amb l'única excepció de la recent obra d'Albert García Espuche.

3. Preguntes que molts autors s'han plantejat amb explícita urgència. Citant-ne tan sols dos exemples, podem recordar entre molts d'altres Joaquim Nadal (1981) o Ernest Belenguer (1986). 
Precisament, l'intent d'aportar una primera aproximació a aquestes respostes constitueix l'objectiu d'aquest treball.

El primer capítol, estudia la incidència de la guerra i de la pau sobre l'economia catalana del segle XVI, ja que les alternances entre guerra i pau sempre han estat decisives en l'evolució de qualsevol espai econòmic en qualsevol moment històric. Això ha de resultar especialment vàlid per a un país tradicionalment abocat al comerç mediterrani, en un segle en el qual aquest mar va viure un conflicte militar intermitent, però excepcionalment llarg i intens.

El segon apartat intenta aportar alguns elements per analitzar les interdependències entre demografia, economia i política en les relacions de Catalunya amb Castella, el Mediterrani (els principals espais econòmics i geogràfics amb els quals s'interrelaciona) i amb la monarquia hispànica (l'àmbit polític en el qual es mou).

I, finalment, el tercer capítol intenta - a través de la figura de Jaume Damiansuna primera aproximació a la relació entre la trajectòria econòmica del país i el pensament politicoeconòmic previ a la revolució de 1640.

A l'entorn de 1545, l'economia catalana disposava d'una enorme oferta de terres sense explotar i d'una gran reserva de mà d'obra masculina nascuda a Occitània i que arribava a Catalunya en el millor moment de la seva capacitat laboral. Dos elements, que, respectivament, van contribuir a mantenir els costos de la terra i els salarials força estables. Especialment aquests darrers.

I, per tant, durant aquest període, el que per a altres va ser l'origen d'un greu problema inflacionari, per a Catalunya va ser un estímul molt important per al seu creixement econòmic.

Un creixement econòmic i demogràfic que es concentra entre 1545 i 1625 (aproximadament) i que es caracteritza per una forta orientació mediterrània, que no oblida totalment el trànsit cap a l'Atlàntic a través dels ports andalusos i, especialment, portuguesos.

Així, a partir de la decada dels 'quaranta, l'economia catalana creix i es diversifica sota l'impuls poderós de l'augment accelerat de la seva població activa ${ }^{4}$. I, simultàniament, els catalans se senten amb forces, d'una banda, per tornar a exercir un lideratge econòmic modest — però cada cop més evident- sobre València i Aragó $^{5}$; i, de l'altra, per reconquerir els vells mercats italians ${ }^{6}$, malgrat totes les difi-

El primer quan afirma que per entendre l'equilibri d'exigències i concessions entre les intitucions catalanes i la monarquia cal «profunditzar en els interessos socials i econòmics de les opcions en pugna i en l'actitud dels diferents sectors socials en pugna» (NADAL I FARRERAS, Joaquim. «Catalunya dins l'imperi hispànic: l'articulació institucional i el seu funcionament», dins Història de Catalunya, Salvat, Barcelona 1981, vol. IV, p. 5). I el segon quan es pregunta si durant el regnat de Felip II, Catalunya realitza un « ¿Viraje de aislamiento o de reencuentro con el mundo mediterráneo tradicional?» o si «¿Podrían evidentemente explicarse las tensiones que van a ir aumentando en Cataluña, respecto al gobierno central, por el desfase de un poder que tiende a frenar y tirar hacia sí a una Cataluña volcada a Europa y crecida demográfica y económicamente?» (BELENGUER, Ernest. La Corona de Aragón en la época de Felipe II, Universidad de Valladolid, Valladolid 1986, p. 16).

4. Simon i TARrés, Antoni (1992). «La població catalana...». p. 220; i SimON, Antoni (1996). La població catalana... p.11-34.

5. Capítols de Corts de 1553.

6. Capítols de Corts de 1564. 
cultats que comporta la competència genovesa i la guerra intermitent — però força sovintejada - en el mar. I, per tant, en coincidència amb cada parèntesi de pau, les relacions comercials amb Itàlia experimenten una successió de poderosos salts endavant.

En efecte, la guerra genera el temor i l'especulació que liquiden el creixement econòmic de Barcelona. Davant qualsevol rumor de guerra, els mercaders no arrisquen els seus vaixells; les importacions de cereals s'aturen; els especuladors acaparen les existències a l'espera de l'augment de preus; els preus es disparen a l'alça; la ciutat es buida ${ }^{7}$. Un efecte reforçat per la interrupció de les exportacions de manufactures; manca de matèries primeres; acumulació d'estocs de productes acabats; acomiadament de menestrals i aprenents. L'atur s'estén per la ciutat, mentre que els preus no deixen de pujar. Un exemple excel-lent dels espasmes econòmics provocats per la guerra.

El resistencialisme fiscal dels catalans potser no era tant el símptoma del seu egoisme o de la seva incapacitat per entendre els designis de la política universal de la monarquia, com el resultat d'una estratègia econòmica profundament racional. En primer terme, perquè a Catalunya la fiscalitat sobre les transaccions comercials era la principal via d'ingressos de la Generalitat. I, en segon lloc — vista l'experiència i les limitacions del mateix poder militar-, potser no és gens estrany que la pau pogués semblar la millor via, per a importants sectors de l'economia catalana ${ }^{8}$.

7. AHB, Registre de lletres closes, 1552, foli 184, dins: CARRERA PuJAL, Jaume (1946). Historia política y..., vol. I, p. 125.

8. Recordem, per exemple, que el gran take off finisecular del comerç marítim barceloní va coincidir amb la firma de la pau de Morgliani de $1581 \mathrm{amb}$ els turcs. El mateix any en què, per primera vegada després de seixanta anys, el trànsit de vaixells al port de València recupera el nivell que havia tingut abans de la forta sotragada de les Germanies. 


\section{NORMES DE COL·LABORACIÓ}

1. Els articles hauran de ser originals i es publicaran en català o castellà. Es presentaran mecanografiats a doble espai, en fulls numerats de mida DIN A4 (30 línies de 60 espais, 280 paraules). Hom recomana que no superin les vint-i-cinc pàgines, incloent-hi gràfiques, notes i bibliografia. A la primera pàgina de l'article constarà la informació següent: títol de l'article, nom i cognoms de l'autor, professió, telèfon i adreça postal i electrònica professional; a la segona pàgina hi haurà un resum de 150 paraules en català, en castellà $i$ en anglès, $i$ entre tres i cinc paraules clau en les tres llengües esmentades, que permetin la classificació/identificació de l'article. Hom trametrà a més una còpia en suport magnètic en qualsevol dels processadors de text habituals.

2. Pel que fa a la bibliografia i a les referències, hom ha de considerar:

Les al-lusions a autors al text aniran acompanyades normalment d'una referència explícita afegida a continuació entre parèntesis (cognom de l'autor, any de publicació i eventualment la pàgina); en el cas d'una cita textual, a continuació del text s'afegirà aquesta referència entre parèntesis, en la qual constarà necessàriament la pàgina. Exemples:

[...] és a dir, no solament de la família aristocràtica o de la de qualsevol altra forma d'agrupació familiar (Petit, 1997).

[...] Les confraries i germandats responien segons Isidoro Moreno (1972: 199) a la doble necessitat d'associar-se en el marc local i d'assegurar-se la salvació eterna.

[...] en paraules de Schumpeter, la economia conquistà entre els escolàstics tardans «si no una existència autònoma, al menys sí una existència ben determinada» (Schumpeter, 1971: 136).

3. A la fi de l'article s'inclourà per ordre alfabètic una bibliografia amb les referències completes que permetin la identificació dels treballs. De la següent manera:

a) quan es tracti d'un llibre:

Castro, A. (1996). La realidad histórica de España. Mèxic: Fondo de Cultura Económica.

(Cognoms de l'autor en minúscules, nom; any de publicació entre parèntesis; títol del llibre en cursiva o subratllat; lloc d'edició; editorial).

b) quan es tracti d'un article:

Asensio, E. (1972-1973). «Notas sobre la historiografía de Américo Castro». Anuario de Estudios Medievales, 8, p. 349-392.

(Cognoms de l'autor en minúscules, nom; any de publicació entre parèntesis; títol de l'article entre cometes; títol de la revista en cursiva o subratllat; volum i número; pàgines inicial i final). 
Cal evitar les notes a peu de pàgina, però si són imprescindibles hauran de numerar-se i agrupar-se després del text de l'article i abans de la bibliografia. Per a les al-lusions i cites s'observaran els mateixos criteris que per a la resta del text.

4. Les taules —única denominació que s'utilitzarà per a tota mena de quadres $\mathrm{i}$ relacions estadístiques - numerats amb xifres aràbigues, aniran en un full apart a continuació de l'article. Tanmateix, s'hauran de referenciar explícitament al text.

5. La il-lustració s'ajustarà a les indicacions següents:

a) Totes les figures s'hauran de presentar en paper blanc, preferentment de mida DIN A4, acompanyades del títol, la llegenda i la font. En un full apart s'afegiran les dades estadístiques amb les quals s'ha elaborat la gràfica. Tots dos fulls portaran al dors, en llapis, el nom i els cognoms de l'autor corresponent en xifres aràbigues. El text ha de fer referència explícita a les gràfiques reproduïdes.

b) Tots els mapes s'hauran de presentar en dues còpies en paper blanc, preferentment de mida DIN A4. Hauran d'estar ben definits. Els títols, la llegenda i la font aniran només a la segona còpia. Tots dos fulls portaran al dors, en llapis, el nom i els cognoms de l'autor corresponent en xifres aràbigues. El text ha de fer referència explícita a les gràfiques reproduïdes.

6. El Consell de redacció es reserva el dret de retornar els articles que no compleixin aquestes normes o, en el seu cas, d'adaptar-los als criteris establerts.

7. El Consell de redacció comunicarà al col-laborador l'acceptació de l'article després de l'oportú examen. 


\section{NORMAS DE COLABORACIÓN}

1. Los artículos habrán de ser originales y se publicarán en castellano o catalán. Se presentarán mecanografiados a doble espacio, en hojas numeradas de tamaño DIN A4 (30 líneas de 60 espacios, 280 palabras). Se recomienda que su extensión no supere las veinticinco páginas, incluyendo gráficos, notas y bibliografía. En la primera página del artículo constará la información siguiente: título del artículo, nombre y apellidos del autor, profesión, teléfono y dirección postal y electrónica profesional; en la segunda página habrá un resumen de 150 palabras en castellano, en catalán y en inglés, y entre tres y cinco palabras clave en las tres lenguas citadas, que permitan la clasificación/identificación del artículo. Se enviará además una copia en soporte magnético en cualquiera de los procesadores de texto habituales.

2. En cuanto a la bibliografía y a las referencias, habrá que atenerse a lo siguiente:

Las alusiones a autores en el texto irán acompañadas normalmente de una referencia explícita añadida a continuación entre paréntesis (apellidos del autor, año de publicación y eventualmente la página); en el caso de una cita textual, a continuación del texto se añadirá esta referencia entre paréntesis, en la que constará necesariamente la página. Ejemplos:

[...] es decir, no ya sólo de la familia aristocrática o de la de cualquier otra forma de agrupación familiar (Petit, 1997).

[...] Las cofradías y hermandades respondían según Isidoro Moreno (1972: 199) a la doble necesidad de asociarse en el marco local y asegurarse la salvación eterna.

[...] En palabras de Schumpeter, la economía conquistó entre los escolásticos tardíos «si no una existencia autónoma, al menos sí una existencia bien determinada» (Schumpeter, 1971: 136).

3. Al final del artículo se incluirá por orden alfabético una bibliografía con las referencias completas que permitan la identificación de los trabajos. Por tanto:

a) cuando se trate de un libro:

Castro, A. (1996). La realidad histórica de España. México: Fondo de Cultura Económica.

(Apellidos del autor en minúsculas, nombre; año de publicación entre paréntesis; título del libro en cursiva o subrayado; lugar de edición; editorial).

b) cuando se trate de un artículo:

Asensio, E. (1972-1973). «Notas sobre la historiografía de Américo Castro». Anuario de Estudios Medievales, 8, p. 349-392.

(Apellidos del autor en minúsculas, nombre; año de publicación entre paréntesis; título del artículo entre comillas; título de la revista en cursiva o subrayado; volumen y número; páginas inicial y final). 
Conviene evitar las notas a pie de página, pero si son imprescindibles deberán numerarse y agruparse después del texto del artículo y antes de la bibliografía. Para las alusiones y citas se observarán los mismos criterios que en el resto del texto.

4. Las tablas —única denominación que se utilizará para todo tipo de cuadros y relaciones estadísticas - numerados en cifras arábigas, irán en una hoja aparte al final del artículo. Sin embargo, habrá que referenciarlos explícitamente en el texto.

5. La ilustración se ajustará a las indicaciones siguientes:

a) Todas las figuras deberán presentarse en papel blanco, preferentemente en tamaño DIN A4, acompañados del título, la leyenda y la fuente. En una hoja aparte se añadirán los datos estadísticos con los cuales se ha elaborado el gráfico. Las dos hojas llevarán al dorso, en lápiz, el nombre y los apellidos del autor y el número correspondiente en cifras arábigas. El texto ha de hacer referencia explícita a los gráficos reproducidos.

b) Todos los mapas deberán presentarse en dos copias en papel blanco, de tamaño preferentemente DIN A4. Deberán estar bien definidos. Los títulos, la leyenda y la fuente irán sólo en la segunda copia. Las dos hojas llevarán al dorso, en lápiz, el nombre y los apellidos del autor y el número correspondiente en cifras arábigas. El texto ha de hacer referencia explícita a los mapas reproducidos.

6. El Consejo de redacción se reserva el derecho de devolver los artículos que no cumplan estas normas o, en su caso, de adaptarlos a éstas.

7. El Consejo de redacción comunicará al colaborador la aceptación del artículo tras el oportuno examen. 


\section{manuSCRITS \\ Revista d'història moderna}

\section{Subscripció, compres i intercanvis:}

Servei de Publicacions de la Universitat Autònoma de Barcelona

Apartat postal 20. 08193 Bellaterra (Barcelona). Spain

Tel. 9358110 22. Fax 9358120 00. E-mail sp@uab.es

\section{Subscripció / Suscripción}

Desitjo subscriure'm a Manuscrits. Revista d'Història Moderna des del número 18 (2000). Preu de subscripció: 2.600 PTA.

Deseo suscribirme a Manuscrits. Revista d'Història Moderna desde el número 18 (2000). Precio de subscripción: 2.600 PTA.

Data:

Fecha

Nom i cognoms:

Nombre y apellidos

Adreça postal:

Dirección postal

Tipus de targeta de crèdit:

Tipo de tarjeta de crédito

Número de la targeta de crèdit:

Número de la tarjeta de crédito

Data de caducitat de la targeta:

Fecha de caducidad de la tarjeta:

Signatura / Firma

Preu de venda unitari dels números endarrerits: núm. 4-5: 1.000 PTA; núm. 6: 825 PTA; núm. 7: 1.000 PTA; núm. 8: 1.500 PTA; núm. 10: 2.500 PTA; núm. 11-16: 1.800 PTA.; núm. 17: 2.600 PTA. Núm. 1, 2 i 3, exhaurits.

* Els subscriptors gaudiran d'un descompte del 15\% sobre el PVP.

Los suscriptores se beneficiaran de un descuento del $15 \%$ sobre el PVP

* Els subscriptors poden acollir-se a la compra de la col-lecció Monografies Manuscrits amb el mateix descompte sobre el preu de venda. Han aparegut fins ara cinc monografies:

Los suscriptores pueden acogerse a la compra de la colección Monografies Manuscrits con el mismo descuento sobre el precio de venta. Han aparecido hasta ahora cinco monografías

1. AA.VV., La cultura del Renaixement. Homenatge al pare Miquel Batllori, 1993 (1.700 PTA).- 2. A. Simon Tarrés, La població catalana a l'edat moderna, 1996 (1.800 PTA).3. AA.VV., Diez años de historiografía modernista, 1997 (1.800 PTA).- 4. J. Antón Pelayo, La herencia cultural. Alfabetización y lectura en la ciudad de Girona (1747-1807), 1998 (2.500 PTA).- 5. A. Espino López, Catalunya durante el reinado de Carlos II. Política y guerra en la frontera catalana, 1679-1697, 1997 (3.000 PTA). 